\title{
Produtividade do milho em sucessão a adubos verdes no sistema de plantio direto e convencional
}

\author{
Marco Antonio Camillo de Carvalho(1), Rogério Peres Soratto(2), Manuel Luiz Ferreira Athayde ${ }^{(3)}$, \\ Orivaldo $\operatorname{Arf}^{(4)}$ e Marco Eustáquio de Sá(4)
}

\begin{abstract}
(1)Eletronorte, Br 422, km 13, CEP 68464-000 Tucuruí, PA. E-mail: camillo@eln.gov.br (2)Unesp, Fac. de Ciências Agronômicas, Campus de Botucatu, Caixa Postal 237, CEP 18603-970 Botucatu, SP. E-mail: soratto@fca.unesp.br (3)Unesp, Fac. de Ciências Agrárias e Veterinárias, Campus de Jaboticabal, Via de Acesso Prof. Paulo Donato Castellane, s/no, CEP 14884-900 Jaboticabal, SP. (4)Unesp, Fac. de Engenharia, Campus de Ilha Solteira, Caixa Postal 31, CEP 15385-000 Ilha Solteira, SP. E-mail: arf@agr.feis.unesp.br, mesa@agr.feis.unesp.br
\end{abstract}

Resumo - A sucessão de culturas a adubos verdes pode melhorar as condições físicas, químicas e biológicas do solo, com conseqüente aumento na produtividade. O objetivo do trabalho foi avaliar características agronômicas e a produtividade do milho, cultivado em sucessão a adubos verdes nos sistemas de plantio direto e de preparo convencional do solo (uma gradagem pesada e duas gradagens leves). O experimento foi realizado em Latossolo Vermelho distrófico, originalmente sob vegetação de Cerrado em Selvíria, MS. O delineamento utilizado foi o de blocos ao acaso, em esquema de parcela subdividida e quatro repetições. Utilizaram-se quatro adubos verdes: mucuna-preta, guandu, crotalária e milheto, e área de pousio (vegetação espontânea). A crotalária cultivada na primavera proporcionou aumento de 18,5\% na produtividade do milho em sucessão, comparada à área de pousio, em ano com precipitação normal, tanto em plantio direto, quanto no sistema de preparo convencional do solo. O sistema convencional de preparo do solo propiciou maior produtividade do milho em ano com ocorrência de veranico.

Termos para indexação: cultivo seqüencial, adubo orgânico, rendimento, manejo do solo, plantio direto, cerrado.

\section{Yield of corn grown after green manures under no-tillage and conventional management system}

\begin{abstract}
The succession of grain crops after green manures can improve physical, chemical and biological soil conditions, with increases on grain yield. The objective of the study was to evaluate the agronomical characteristics and the yield of corn grown after green manures under no-tillage and conventional tillage (one disc harrow and two levelling harrow) systems. The experiment was carried out in a Typic Haplustox, covered by savanna vegetation, in Selvíria, MS, Brazil. The experimental design used was randomized blocks, in a split plot scheme, with four replications. Four green manures were used: black velvet bean, pigeon pea, sunn hemp and millet and fallow area (spontaneous vegetation). The sunn hemp previously grown in spring increased $18.5 \%$ the corn yield, compared to the fallow, on a year without dry periods, in both no-tillage and conventional tillage systems. The conventional tillage provided the largest grain yield in years with dry periods.
\end{abstract}

Index terms: sequential cropping, organic fertilizers, soil management, no-tillage system, savanna.

\section{Introdução}

A cultura do milho tem um alto potencial produtivo, alcançando $10 \mathrm{t} \mathrm{ha}^{-1}$ de grãos, no Brasil, em condições experimentais e por agricultores que adotam tecnologias adequadas. No entanto, o que se observa na prática são produtividades muito baixas e irregulares, cerca de $3,5 \mathrm{t} \mathrm{ha}^{-1}$ de grãos (Conselho Nacional de Abastecimento, 2003). Segundo Coelho \& França (1995), a fertilidade do soloé um dos principais fatores responsáveis por essa baixa produtividade.
No Cerrado, como nas demais regiões tropicais, a mineralização da matéria orgânica é bastante rápida, por causa da elevada temperatura e umidade do solo, durante boa parte do ano (Sanchez \& Logan, 1992). Essa característica impossibilita a adequada reposição de nutrientes nos sistemas convencionais de manejo dos solos e das culturas (Derpsch, 1997; Kluthcouski et al., 2000).

A sucessão de cultivos distintos contribui para manter o equilíbrio dos nutrientes no solo e aumentar a sua fertilidade, além de permitir melhor utilização dos 
insumos agrícolas. A adição regular de resíduos de adubos verdes aos vários solos dos trópicos, nos quais a matéria orgânica apresenta-se entre $2 \%$ e $3 \%$, praticamente inativa; contribui para a conservação do solo e da água, promovendo, principalmente, a melhoria da estrutura que favorece a aeração e a infiltração de água no solo, possibilitando maior penetração do sistema radicular (Igue, 1984; Lal, 1986). Além disso, propicia melhor aproveitamento de adubos químicos e redução nos custos com adubação mineral, uma vez que o adubo verde promove aumento da atividade biológica do solo (Hernani et al., 1995). Contudo, a resposta das culturas depende da interação de fatores como a natureza do material (relação $\mathrm{C} / \mathrm{N}$, teor de lignina), as propriedades do solo, as características da cultura principal e o clima (Lal, 1986; Amabile et al., 1994).

O objetivo principal da adoção de métodos de preparo do solo é controlar plantas daninhas e favorecer o desenvolvimento e produtividade das culturas. No entanto, o uso intensivo do solo pode predispô-lo à formação de camadas compactadas, à redução da estabilidade dos agregados e ao aparecimento, em maior número, de microporos, aumentando a propensão à perda de solo por erosão (Souza, 1988).

A manutenção de resíduos culturais na superfície do solo no plantio direto proporciona aumento da retenção de água e maior proteção do solo contra o impacto direto das chuvas (Igue, 1984), em relação a sua incorporação mediante o preparo convencional. O não revolvimento do solo leva a uma decomposição mais lenta e gradual do material orgânico, tendo como conseqüência a melhoria das condições físicas, químicas e biológicas no solo, que irão repercutir em sua fertilidade e na produtividade das culturas (Moody et al., 1961).

Na cultura do milho, os resultados referentes aos diferentes manejos do solo são bastante diferenciados. Maiores rendimentos de milho no sistema de plantio direto, em relação a outros sistemas de manejo do solo, foram relatados por Possamai et al. (2001), e menores, por Fancelli \& Favarin (1989).

O objetivo deste trabalho foi avaliar as características agronômicas e a produtividade da cultura do milho em sucessão a adubos verdes nos sistemas de plantio direto e de preparo convencional do solo (uma gradagem pesada e duas gradagens leves).

\section{Material e métodos}

O trabalho foi realizado nos anos agrícolas de 1997/1998 e 1998/1999, em área experimental perten- cente à Faculdade de Engenharia de Ilha Solteira Unesp, Município de Selvíria, MS, localizada a 51 ${ }^{\circ} 22^{\prime} \mathrm{W}$ e $20^{\circ} 22^{\prime} \mathrm{S}$, com altitude de $335 \mathrm{~m}$. O solo do local é um Latossolo Vermelho distrófico típico argiloso, A moderado, hipodistrófico, álico, caulinítico, férrico, compactado, muito profundo, moderadamente ácido (Embrapa, 1999). O clima, conforme a classificação de Köppen, é do tipo Aw, com precipitação média anual de $1.370 \mathrm{~mm}$, concentrada, principalmente, de outubro a março. A temperatura média anual do ar é de $23,5^{\circ} \mathrm{C}$, e a umidade relativa do ar está entre $70 \%$ e $80 \%$ (média anual). As precipitações registradas durante a fase experimental são mostradas na Figura 1.

Antes da instalação do experimento, foi realizada amostragem de solo para a determinação das características químicas, na camada de $0-0,20 \mathrm{~m}$, de acordo com método proposto por Raij \& Quaggio (1983), cujos resultados foram: $27,0 \mathrm{~g} \mathrm{dm}^{-3}$ de matéria orgânica, $\mathrm{pH}$ $\left(\mathrm{CaCl}_{2}\right), 5,3 ; 13,0 \mathrm{mg} \mathrm{dm}^{-3}$ de P; $1,1 \mathrm{mmol}_{\mathrm{c}} \mathrm{dm}^{-3} \mathrm{de} \mathrm{K}$; 28,0 $\mathrm{mmol}_{\mathrm{c}} \mathrm{dm}^{-3} \mathrm{de} \mathrm{Ca} ; 10,3 \mathrm{mmol}_{\mathrm{c}} \mathrm{dm}^{-3} \mathrm{de} \mathrm{Mg}$ e $57 \%$ de saturação por bases.

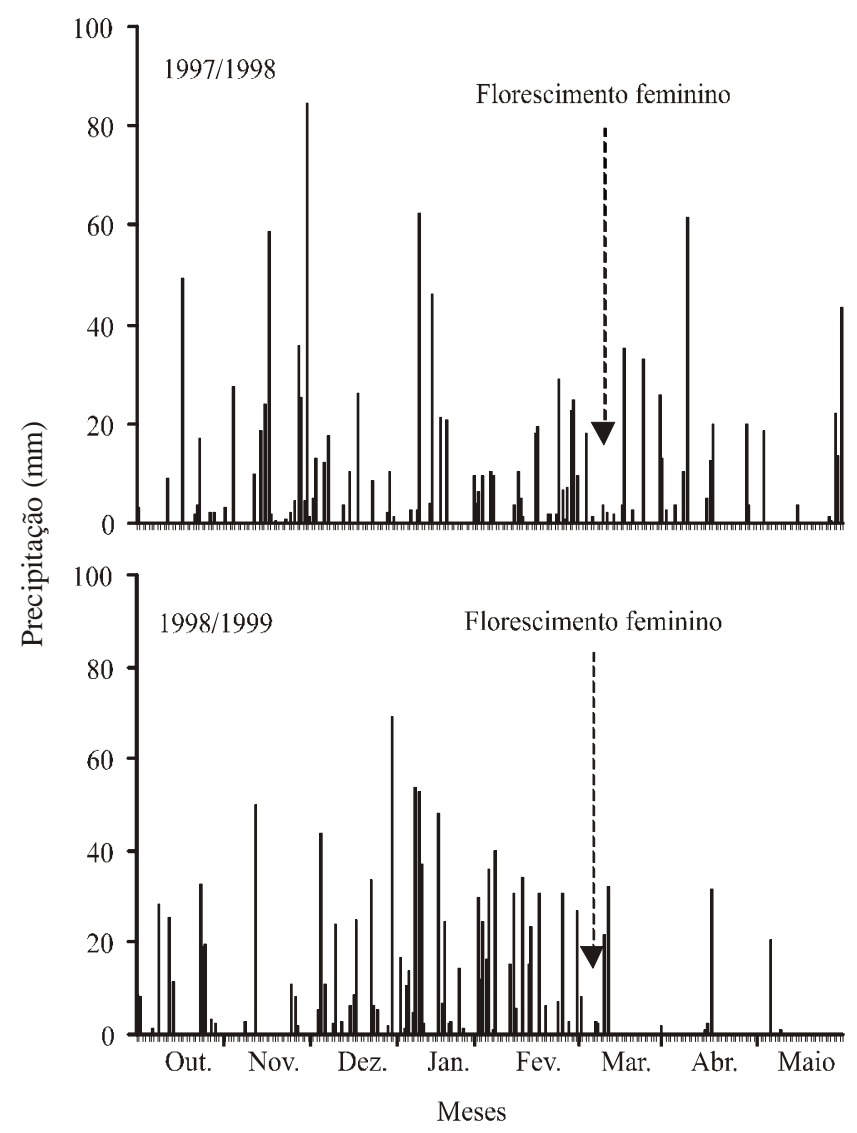

Figura 1. Valores diários de precipitação $\left(\mathrm{mm} \mathrm{dia}^{-1}\right)$, obtidos na área experimental, durante o período de outubro a maio, nos anos agrícolas de 1997/1998 e 1998/1999, e datas de florescimento feminino do milho. 
O delineamento experimental utilizado foi o de blocos ao acaso, no esquema em parcelas subdivididas, com quatro repetições. As parcelas foram constituídas por quatro adubos verdes: mucuna-preta (Mucuna aterrima (Piper \& Tracy) Merr.); guandu (Cajanus cajan (L.) Millsp.); crotalária (Crotalaria juncea L.) e milheto (Pennisetum americanum L.) e área de pousio (vegetação espontânea). Na área em pousio, predominavam espécies como Panicum maximum Jacq. e Brachiaria decumbens (Stapf.) Prain. As subparcelas foram constituídas por dois sistemas de manejo do solo: plantio direto (semeadura sem preparo prévio do solo) e sistema de preparo convencional (preparo do solo com grade pesada à profundidade de $0,15-0,20 \mathrm{~m}$ e em seguida foram feitas duas gradagens com grade leve à profundidade de $0,10-0,12 \mathrm{~m})$. A área de cada subparcela era de $42 \mathrm{~m}^{2}$ (7x6 m), separadas umas das outras por uma distância de $7 \mathrm{~m}$.

O solo da área experimental, anteriormente cultivado com arroz, foi preparado por meio de uma aração, com arado de discos reversíveis, de tração motorizada à profundidade de $0,20-0,25 \mathrm{~m}$ e duas gradagens, com grade leve à profundidade de $0,10-0,12 \mathrm{~m}$, sendo a primeira após a aração (30/4/1997) e, a segunda, antes da semeadura do feijão de inverno (15/5/1997), para uniformização da área. Esse preparo de solo foi repetido antes de cada plantio. Em outubro de 1997, nas áreas destinadas ao plantio direto, foi aplicado o herbicida glifosate (2.400 $\mathrm{g} \mathrm{ha}^{-1}$ do i.a.). O restante da área recebeu preparo de solo convencional (uma gradagem pesada e duas gradagens leves).

A semeadura dos adubos verdes foi realizada mecanicamente em 19/10/1997 e 8/10/1998, em sucessão ao feijoeiro de inverno. O espaçamento e densidade de semeadura utilizados foram: $0,45 \mathrm{~m}$ entrelinhas e cinco sementes por metro para a mucuna-preta; $0,45 \mathrm{~m}$ entrelinhas e 30 sementes por metro para a crotalária e o guandu e, 0,225 m entrelinhas e 120 sementes por metro para o milheto. Todas as espécies foram semeadas sem a utilização de adubação básica ou de cobertura. Em 17/12/1997 e 21/12/1998 determinou-se a massa da matéria seca (MS) da parte aérea, coletando-se, aleatoriamente, duas subamostras de $1,0 \mathrm{~m}^{2}$ por subparcela, que constituíram uma única amostra. O material coletado foi levado à estufa, a $65^{\circ} \mathrm{C}$ até atingir massa constante e, a seguir, pesado.

Nas mesmas datas em que foram realizadas as avaliações da MS dos adubos verdes e da vegetação es- pontânea, que ocorreu na área de pousio, nas subparcelas destinadas ao sistema de plantio direto, a vegetação foi dessecada mediante aplicação de herbicida glifosate (2.400 $\mathrm{g} \mathrm{ha}^{-1}$ do i.a.). Nas subparcelas destinadas ao sistema de preparo convencional, a vegetação foi roçada e o solo foi preparado com uma gradagem pesada e duas gradagens leves, como descrito anteriormente.

O milho foi semeado em 7/1/1998 e 28/12/1998, mecanicamente, utilizando-se o híbrido Exeller, com seis sementes por metro de sulco e $0,90 \mathrm{~m}$ entrelinhas, para obtenção de uma população de 60.000 plantas ha $^{-1}$. A adubação básica foi de $285 \mathrm{~kg} \mathrm{ha}^{-1}$ da fórmula NPK 8-28-16, nas duas safras. No cálculo da quantidade de fertilizante, foram consideradas as características químicas do solo, a produtividade esperada, e as recomendações de Raij et al. (1996). Aos 32 dias após a emergência das plantas, efetuou-se a adubação em cobertura com 50 e $60 \mathrm{~kg} \mathrm{ha}^{-1}$ de $\mathrm{N}$, na forma de sulfato de amônio, em 1997/1998 e em 1998/1999, respectivamente.

No período de outono-inverno de 1998, a área experimental foi cultivada com a cultura do feijão após a colheita do milho, porém, os sistemas de manejo do solo foram mantidos, em cada subparcela, de acordo com o estabelecido para os adubos verdes e para o milho. Nos tratamentos de plantio direto o feijão foi semeado sobre a palhada da cultura do milho.

O florescimento pleno da cultura foi atingido em 13/3/1998 e 1@/3/1999. Na obtenção da produção de grãos, foram colhidas em 15/5/1998 e 23/4/1999, as duas linhas centrais de cada subparcela, perfazendo uma área útil de $9,0 \mathrm{~m}^{2}$. Nessa ocasião, também foram determinadas a população de plantas, altura de planta e de inserção da espiga, massa da espiga, número de grãos por espiga e massa de 100 grãos. A umidade dos grãos foi corrigida para $0,13 \mathrm{~kg} \mathrm{~kg}^{-1}$.

Antes da semeadura dos adubos verdes, em 1997 e 1998, foi determinada a densidade do solo em vinte pontos por parcela, pelo método do anel volumétrico, nas profundidades de $0-0,1 ; 0,1-0,2$ e $0,2-0,4 \mathrm{~m}$.

Os dados de massa de MS dos adubos verdes e das características da cultura do milho foram submetidos à análise de variância para cada ano agrícola. Posteriormente, procedeu-se à análise conjunta dos dois anos agrícolas, uma vez que a razão entre o maior e o menor quadrado médio residual de cada ano não foi superior a sete, para verificar se houve efeito dos anos e das interações entre o ano agrícola e os demais fatores estudados (Banzatto \& Kronka, 1989). As médias foram comparadas pelo teste de Tukey, a 5\% de probabilidade. 


\section{Resultados e Discussão}

Nos dois anos, o guandu apresentou a menor massa de MS (2.856 kg ha-1), menor, inclusive, que a da área de pousio (Tabela 1). Amabile et al. (2000) constataram que, em espécies como guandu, mucuna-preta e crotalária, o florescimento ocorre cerca de 120-140 dias após a emergência (DAE), quando semeados em novembro, na região Centro-Oeste. Entretanto, Wutke (1993) relatou que a massa de MS no Estado de São Paulo varia de 8 a $12 \mathrm{tha}^{-1}$ (guandu) e de 6 a $8 \mathrm{t} \mathrm{ha}^{-1}$ (mucuna-preta), quando o manejo ocorre no florescimento pleno. O manejo dos adubos verdes ocorreu cerca de $60 \mathrm{DAE}$, ou seja, bem antes do florescimento, isso explica o baixo valor da massa de MS.

O sistema de manejo do solo não interferiu, de forma significativa, na MS, tanto dos adubos verdes quanto da área de pousio. Pela análise conjunta dos dados (Tabela 1), constatou-se interação significativa apenas entre sistema de manejo do solo e ano agrícola. No sistema de plantio direto, o maior valor de massa de MS dos adubos verdes foi observado em 1997/1998, provavelmente, devido a maior precipitação ocorrida naquele ano. Segundo Santos et al. (1995), sob condições de baixa precipitação, o sistema de plantio direto é mais eficiente na manutenção da umidade disponível do solo, principalmente, em virtude da permanência de palhada na superfície. Contudo, neste trabalho, a cultura antecessora

Tabela 1. Massa de matéria seca da parte aérea $\left(\mathrm{kg} \mathrm{ha}^{-1}\right)$ dos adubos verdes e vegetação espontânea em plantio direto e preparo convencional, nos anos agrícolas de 1997/1998 e 1998/1999(1).

\begin{tabular}{lcc}
\hline Tratamentos & $1997 / 1998$ & $1998 / 1999$ \\
\hline Mucuna & $4.783 \mathrm{bA}$ & Adubo verde \\
Guandu & $2.856 \mathrm{bA}$ & $3.400 \mathrm{bcA}$ \\
Milheto & $9.458 \mathrm{aA}$ & $2.100 \mathrm{cA}$ \\
Crotalária & $5.330 \mathrm{abA}$ & $7.300 \mathrm{aA}$ \\
Pousio & $5.149 \mathrm{abA}$ & $3.500 \mathrm{bA}$ \\
\hline CV $(\%)$ & 42,1 & $4.100 \mathrm{bA}$ \\
\hline & & 24,9 \\
\hline Plantio direto & Sistema de manejo \\
Preparo convencional & $5.570 \mathrm{aA}$ & $3.540 \mathrm{aB}$ \\
\hline CV $(\%)$ & 40,2 & $4.620 \mathrm{aA}$ \\
\hline
\end{tabular}

${ }^{(1)}$ Médias seguidas de letras distintas, minúscula na coluna, para cada fator (adubo verde e sistema de manejo) e maiúscula na linha, para ano (análise conjunta), diferem entre si, a 5\% de probabilidade, pelo teste de Tukey. às espécies de adubo verde e ao pousio foi o feijão, que produz pequena quantidade de palha, com baixa relação $\mathrm{C} / \mathrm{N}$, fazendo com que ela seja rapidamente decomposta, deixando o solo descoberto em um curto período de tempo. No sistema de preparo convencional do solo, a massa de MS dos adubos verdes foi semelhante em ambas as estações de cultivo, indicando que o preparo do solo pode ter favorecido o estabelecimento e o crescimento das raízes em profundidade, com conseqüente melhor aproveitamento da água armazenada no solo.

A população de plantas, no cultivo de milho, sofreu efeito do manejo do solo, no segundo ano de cultivo (Tabela 2). O preparo convencional do solo proporcionou população de plantas superior ao sistema de plantio direto, em 1998/1999. A menor população de plantas verificada no sistema de plantio direto, no ano agrícola de 1998/1999, pode estar relacionada à profundidade de semeadura, pois foi utilizada a mesma regulagem da semeadora nos dois sistemas de manejo do solo. Assim, no sistema de plantio direto, a maior densidade do solo, na camada de $0-0,1 \mathrm{~m}$, provavelmente, dificultou a deposição das sementes na profundidade adequada, fazendo com que ficassem próximo à superfície, o que pode ter prejudicado a germinação e provocado queda e morte de plantas durante o ciclo da cultura, conseqüentemente reduzindo a população final (Figura 2). Pela análise conjunta, verificou-se efeito significativo da interação ano x sistema de manejo. Apenas o sistema de preparo convencional sofreu efeito de ano agrícola, com população de plantas superior no segundo, evidenciando que a menor densidade do solo pode ter favorecido o estabelecimento da cultura.

Os adubos verdes não influenciaram a altura de planta e a inserção da espiga. O sistema de preparo convencional favoreceu o desenvolvimento vegetativo da planta, já que em 1997/1998 proporcionou maior altura de plantas e, em 1998/1999, proporcionou alturas de inserção da espiga superiores a do sistema de plantio direto (Tabela 2). A altura de planta não foi influenciada pelo ano agrícola, porém a altura de inserção da espiga, no sistema de plantio direto, apresentou maior valor em 1998/1999.

Os componentes da produção não foram afetados significativamente pelos adubos verdes no ano agrícola de 1997/1998. No entanto, no tratamento em que a cultura antecessora foi a crotalária, a produtividade de grãos foi $18 \%$ superior ao tratamento de pousio (Tabela 3). As leguminosas, de modo geral, possuem capacidade de fixar $\mathrm{N}$ atmosférico em simbiose com Rhizobium e 
Tabela 2. Estande final, altura de planta e altura de inserção da espiga do milho cultivado em sucessão a adubos verdes, em plantio direto e preparo convencional, nos anos agrícolas de 1997/1998 e 1998/1999(1).

\begin{tabular}{|c|c|c|c|c|c|c|}
\hline \multirow[t]{2}{*}{ Tratamentos } & \multicolumn{2}{|c|}{$\begin{array}{l}\text { População de plantas } \\
\left.\text { (plantas ha- }{ }^{-1}\right)\end{array}$} & \multicolumn{2}{|c|}{ Altura de planta (m) } & \multicolumn{2}{|c|}{$\begin{array}{c}\text { Altura de inserção } \\
\text { da espiga }(\mathrm{m})\end{array}$} \\
\hline & $1997 / 1998$ & $1998 / 1999$ & $1997 / 1998$ & $1998 / 1999$ & $1997 / 1998$ & $1998 / 1999$ \\
\hline & \multicolumn{6}{|c|}{ Adubo verde } \\
\hline Mucuna & $52.920 \mathrm{aA}$ & $46.110 \mathrm{aA}$ & $2,05 \mathrm{aA}$ & $2,03 \mathrm{aA}$ & $1,11 \mathrm{aA}$ & $1,16 \mathrm{aA}$ \\
\hline Guandu & $48.470 \mathrm{aA}$ & $45.550 \mathrm{aA}$ & $2,02 \mathrm{aA}$ & $1,97 \mathrm{aA}$ & $1,06 \mathrm{aA}$ & $1,12 \mathrm{aA}$ \\
\hline Milheto & $52.220 \mathrm{aA}$ & $46.530 \mathrm{aA}$ & $2,02 \mathrm{aA}$ & $1,98 \mathrm{aA}$ & $1,09 \mathrm{aA}$ & $1,13 \mathrm{aA}$ \\
\hline Crotalária & $48.470 \mathrm{aA}$ & $48.750 \mathrm{aA}$ & $2,04 \mathrm{aA}$ & $2,04 \mathrm{aA}$ & $1,10 \mathrm{aA}$ & $1,16 \mathrm{aA}$ \\
\hline Pousio & $51.250 \mathrm{aA}$ & $43.470 \mathrm{aA}$ & $2,06 \mathrm{aA}$ & $2,02 \mathrm{aA}$ & $1,05 \mathrm{aA}$ & $1,14 \mathrm{aA}$ \\
\hline \multirow[t]{2}{*}{$\mathrm{CV}(\%)$} & 10,6 & 8,5 & 6,6 & 6,8 & 8,9 & 8,7 \\
\hline & \multicolumn{6}{|c|}{ Sistema de manejo } \\
\hline Plantio direto & $44.610 \mathrm{bA}$ & $48.170 \mathrm{aA}$ & $2,02 \mathrm{aA}$ & $1,95 \mathrm{bA}$ & $1,01 \mathrm{bB}$ & $1,12 \mathrm{aA}$ \\
\hline Preparo convencional & $56.720 \mathrm{aA}$ & $44.000 \mathrm{aB}$ & $2,05 \mathrm{aA}$ & $2,07 \mathrm{aA}$ & $1,16 \mathrm{aA}$ & $1,16 \mathrm{aA}$ \\
\hline $\mathrm{CV}(\%)$ & 10,9 & 9,0 & 5,0 & 3,8 & 8,8 & 5,1 \\
\hline
\end{tabular}

${ }^{(1)}$ Médias seguidas de letras distintas, minúsculas na coluna, para cada fator (adubo verde e sistema de manejo) e maiúsculas na linha, para ano (análise conjunta), diferem entre si, a 5\% de probabilidade, pelo teste de Tukey.

baixa relação $\mathrm{C} / \mathrm{N}$, o que favorece a rápida decomposição e liberação desse nutriente para a cultura sucedânea (Ceretta et al., 1994). Além disso, deve considerarse que, a adição de material orgânico mediante a adubação verde proporciona modificações gerais nas propriedades físicas, químicas e biológicas do solo (De-Polli $\&$ Chada, 1989). Assim, a maior produtividade de milho, proporcionada pela crotalária em relação ao pousio, pode ser explicada pela capacidade que essa espécie tem em fornecer $\mathrm{N}$ para o milho em sucessão, já que, na área de pousio, predominavam gramíneas. Aliado a isso, devese mencionar o fato de ter sido essa a leguminosa que apresentou maior quantidade de MS no primeiro ano agrícola (Tabela 1 ).

Em relação à massa de espiga, número de grãos por espiga e massa de 100 grãos, o sistema de plantio direto foi inferior ao sistema convencional, no ano agrícola 1997/ 1998 (Tabela 3). A maior mobilização de $\mathrm{N}$ no início do sistema de plantio direto e a decomposição mais lenta dos resíduos culturais, que ocorre nesse sistema, pode ter prejudicado a adequada nutrição da cultura e contribuído para os menores valores dos componentes da produção, observados no primeiro ano de cultivo. No entanto, o maior número de grãos por espiga e a maior massa de 100 grãos, obtidos no plantio convencional, resultaram em maior massa de espiga sem palha, mas não foram suficientes para proporcionar diferença na produtividade de grãos. Kluthcouski et al. (2000), estudando o efeito do manejo do solo no rendimento do

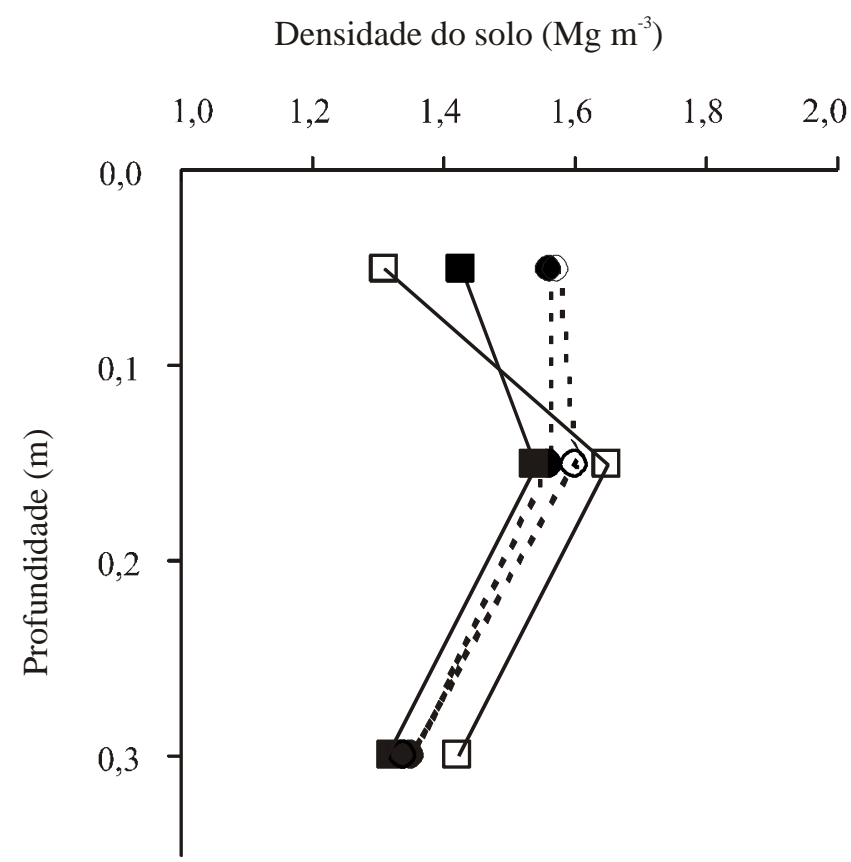

Figura 2. Densidade do solo em razão dos sistemas de plantio direto $(\mathbf{O})$ e preparo convencional $(\boldsymbol{\square})$, no ano agrícola $1997 / 1998$ e nos sistemas de plantio direto (O) e preparo convencional (ם), no ano agrícola 1998/1999.

milho, em Latossolo Roxo, no Estado de Goiás, não verificaram diferença significativa entre o plantio direto e o convencional de preparo com grade pesada.

No ano agrícola de 1998/1999, os adubos verdes proporcionaram diferenças significativas em relação à massa de espiga e número de grãos por espiga (Tabela 3). 
Tabela 3. Massa da espiga seca sem palha, número de grãos por espiga, massa de 100 grãos e produtividade de grãos do milho cultivado em sucessão a adubos verdes, em plantio direto e preparo convencional, nos anos agrícolas de 1997/1998 e 1998/ $1999^{(1)}$.

\begin{tabular}{|c|c|c|c|c|c|c|c|c|}
\hline \multirow[t]{2}{*}{ Tratamentos } & \multicolumn{2}{|c|}{$\begin{array}{l}\text { Massa da espiga } \\
\text { sem palha }(\mathrm{g})\end{array}$} & \multicolumn{2}{|c|}{$\begin{array}{l}\text { Número de grãos } \\
\text { por espiga }\end{array}$} & \multicolumn{2}{|c|}{$\begin{array}{l}\text { Massa de } 100 \text { grãos } \\
\text { (g) }\end{array}$} & \multicolumn{2}{|c|}{$\begin{array}{l}\text { Produtividade } \\
\quad\left(\mathrm{kg} \mathrm{ha}^{-1}\right)\end{array}$} \\
\hline & $1997 / 1998$ & 1998/1999 & $1997 / 1998$ & $1998 / 1999$ & $1997 / 1998$ & $1998 / 1999$ & $1997 / 1998$ & 1998/1999 \\
\hline & \multicolumn{8}{|c|}{ Adubo verde } \\
\hline Mucuna & $173,3 \mathrm{aA}$ & $110,6 a b B$ & $536 \mathrm{aA}$ & $454 \mathrm{aB}$ & $31,0 \mathrm{aA}$ & $21,9 \mathrm{aB}$ & $6.767 \mathrm{abA}$ & $4.711 \mathrm{aB}$ \\
\hline Guandu & $175,0 \mathrm{aA}$ & $117,0 \mathrm{aB}$ & $551 \mathrm{aA}$ & $440 \mathrm{abB}$ & $30,4 \mathrm{aA}$ & $24,7 \mathrm{aB}$ & $6.945 \mathrm{abA}$ & $4.413 \mathrm{aB}$ \\
\hline Milheto & $179,9 \mathrm{aA}$ & $83,2 \mathrm{cB}$ & $565 \mathrm{aA}$ & $389 \mathrm{bB}$ & $28,5 \mathrm{aA}$ & $21,5 \mathrm{aB}$ & $7.201 \mathrm{abA}$ & $4.419 \mathrm{aB}$ \\
\hline Crotalária & $180,4 \mathrm{aA}$ & $99,8 \mathrm{bB}$ & $564 \mathrm{aA}$ & 427abB & $29,7 \mathrm{aA}$ & $21,6 \mathrm{aB}$ & $7.532 \mathrm{aA}$ & $4.374 \mathrm{aB}$ \\
\hline Pousio & $173,0 \mathrm{aA}$ & $102,3 \mathrm{bB}$ & $533 \mathrm{aA}$ & 431abB & $30,5 \mathrm{aA}$ & $23,1 \mathrm{aB}$ & $6.351 \mathrm{bA}$ & $4.524 \mathrm{aB}$ \\
\hline \multirow[t]{2}{*}{$\mathrm{CV}(\%)$} & 6,4 & 11,7 & 6,5 & 8,2 & 6,7 & 10,6 & 10,5 & 13,0 \\
\hline & \multicolumn{8}{|c|}{ Sistema de manejo } \\
\hline Plantio direto & $166,6 \mathrm{bA}$ & $101,9 \mathrm{aB}$ & $527 \mathrm{bA}$ & $429 \mathrm{aB}$ & $28,9 \mathrm{bA}$ & $22,5 \mathrm{aB}$ & $6.767 \mathrm{aA}$ & $4.152 \mathrm{bB}$ \\
\hline Preparo convencional & $186,0 \mathrm{aA}$ & $103,3 \mathrm{aB}$ & $572 \mathrm{aA}$ & $428 \mathrm{aB}$ & $31,1 \mathrm{aA}$ & $22,6 \mathrm{aB}$ & $7.150 \mathrm{aA}$ & $4.825 \mathrm{aB}$ \\
\hline $\mathrm{CV}(\%)$ & 8,2 & 13,5 & 5,7 & 10,1 & 6,8 & 10,5 & 12,4 & 9,3 \\
\hline
\end{tabular}

${ }^{(1)}$ Médias seguidas de letras distintas, minúsculas na coluna, para cada fator (adubo verde e sistema de manejo) e maiúsculas na linha, para ano (análise conjunta), diferem entre si, a $5 \%$ de probabilidade, pelo teste de Tukey.

Porém, essa diferença não interferiu na produtividade de grãos. Ceretta et al. (1994) verificaram que o cultivo de leguminosas na primavera é uma técnica eficiente no aumento da disponibilidade de $\mathrm{N}$ para o milho em sucessão, principalmente, quando estas são incorporadas ao solo (preparo convencional).

No segundo ano o sistema de manejo do solo não afetou a massa de espiga, o número de grãos por espiga e a massa de 100 grãos, porém o sistema de preparo convencional proporcionou maior produtividade de grãos, o que pode ser explicado pela maior população de plantas nesse sistema, que se traduziu em maior produtividade (Tabela 3). Além do que, o revolvimento do solo, mediante o preparo convencional, pode ter favorecido o desenvolvimento radicular da cultura do milho, já que diminuiu a densidade na camada mais superficial do solo (Figura 2), permitindo maior resistência da cultura a períodos de estiagem, que ocorreram após o florescimento (Figura 1). Centurion \& Demattê (1992), trabalhando no mesmo tipo de solo, também obtiveram menor produtividade de grãos do milho cultivado sob o sistema de plantio direto, quando comparado com diferentes sistemas de preparo do solo. Os autores recomendaram a subsolagem, preferencialmente na linha do milho (Box \& Langdale, 1984), visando romper a camada compactada que se forma próximo da superfície, no sistema de plantio direto, o que poderá facilitar o crescimento das raízes.
Por meio da análise conjunta dos dados, verificou-se efeito significativo das interações ano agrícola $\mathrm{x}$ adubo verde e ano agrícola x sistema de manejo, para os componentes da produção e produtividade de grãos (Tabela 3). No ano agrícola de 1998/1999, os valores de massa da espiga sem palha, número de grãos por espiga, massa de 100 grãos e produtividade de grãos, em todos os tratamentos, foram menores do que no ano anterior. Durante o ciclo da cultura do milho, foram registrados $672 \mathrm{~mm}$ de chuva em 1997/1998 e $788 \mathrm{~mm}$ em 1998/ 1999. Porém, no segundo ano de cultivo, após o florescimento da cultura, houve ocorrência de poucas chuvas e grandes períodos de estiagem (Figura 1), o que prejudicou sensivelmente o enchimento dos grãos, em todos os tratamentos, já que, de acordo com Eck (1986), as fases mais sensíveis à deficiência hídrica na cultura do milho, em ordem decrescente, são: florescimento, enchimento de grãos e desenvolvimento vegetativo.

\section{Conclusões}

1. A crotalária cultivada na primavera proporciona maior produtividade do milho em sucessão comparada à área de pousio, em ano com precipitação normal, tanto em plantio direto, quanto no sistema de preparo convencional do solo.

2. O sistema convencional de preparo do solo propicia maior produtividade do milho em ano com ocorrência de veranico. 


\section{Agradecimento}

À Fapesp pelo apoio financeiro.

\section{Referências}

AMABILE, R.F.; CORREIA, J.R.; FREITAS, P.L. de; BLANCANEAUX, P.; GAMALIEL, J. Efeito do manejo de adubos verdes na produção de mandioca (Manihot esculenta Crantz). Pesquisa Agropecuária Brasileira, v.29, p.1193-1199, 1994.

AMABILE, R.F.; FANCELLI, A.L.; CARVALHO, A.M. Comportamento de espécies de adubos verdes em diferentes épocas de semeadura e espaçamentos na região dos cerrados. Pesquisa Agropecuária Brasileira, v.35, p.47-54, 2000.

BANZATTO, D.A.; KRONKA, S.N. Experimentação agrícola Jaboticabal: Funep, 1989. 247p.

BOX, J.E.; LANGDALE, G.W. The effects of in row subsoil tillage and soil water in corn yields in the southeastern coastal plain of the United States. Soil \& Tillage Research, v.4, p.67-78, 1984.

CENTURION, J.F.; DEMATTÊ, J.L.I. Sistemas de preparo do solo de cerrado: efeitos nas propriedades físicas e na cultura do milho. Pesquisa Agropecuária Brasileira, v.27, p.315-324, 1992.

CERETTA, C.A.; AITA, C.; BRAIDA, J.A.; PAVINATO, A.; SALET, R.L. Fornecimento de nitrogênio por leguminosas para o milho em sucessão nos sistema de cultivo mínimo e convencional. Revista Brasileira de Ciência do Solo, v.18, p.215-220, 1994.

COELHO, A.M.; FRANÇA, G.E. de. Seja o doutor do seu milho: nutrição e adubação. 2.ed. Piracicaba: Potafos, 1995. 9p.

CONSELHO NACIONAL DE ABASTECIMENTO (Brasília, DF). Comparativo da área, produção e produtividade: safras 2001/ 2002 e 2002/2003. Disponível em: 〈http://www.conab.gov.br/safras.asp〉. Acesso em: 23 set. 2003

DE-POLLI, H.; CHADA, S. de S. Adubação verde incorporada ou em cobertura na produção de milho em solo de baixo potencial de produtividade. Revista Brasileira de Ciência do Solo, v.13, p.287293, 1989.

DERPSCH, R. Importancia de la siembra directa para obtener la sustentabilidad de la producción agrícola. In: CONGRESO NACIONAL DE ASOCIACIÓN ARGENTINA DE PRODUCTORES EN SIEMBRA DIRECTA, 5., 1997, Mar del Plata. Conferencias. Rosario: Asociación Argentina de Productores en Siembra Directa, 1997. p.153-176.

ECK, H.U. Effects of water deficits on yield, yield components and water use efficiency of irrigated corn. Agronomy Journal, v.75, p.1035-1040, 1986.

EMBRAPA. Centro Nacional de Pesquisa de Solos (Rio de Janeiro, RJ). Sistema brasileiro de classificação dos solos. Brasília: EmbrapaSPI; Embrapa-CNPS, 1999. 412p.

FANCELLI, A.L.; FAVARIN, J.L. Desempenho da cultura do milho em plantio direto e convencional. In: FANCELLI, A.L. (Coord.). Plantio direto no Estado de São Paulo. Piracicaba: Esalq, 1989. p.174-175.
HERNANI, L.C.; ENDRES, V.C.; PITOL, C.; SANTON, J.C. Adubos verdes de outono/inverno no Mato Grosso do Sul. Dourados: Embrapa-CPAO, 1995. 93p.

IGUE, K. Dinâmica da matéria orgânica e seus efeitos nas propriedades do solo. In: ADUBAÇÃO verde no Brasil. Campinas: Fundação Cargill, 1984. p.232-267.

KLUTHCOUSKI, J.; FANCELLI, A.L.; DOURADO-NETO, D.; RIBEIRO, C.M.; FERRARO, L.A. Manejo do solo e o rendimento de soja, milho, feijão e arroz em plantio direto. Scientia Agricola, v.57, p.97-104, 2000 .

LAL, R. Soil surface management in the tropics for intensive land use and high and sustained production. Advances in Soil Sciences, v.5, p.1-109, 1986.

MOODY, J.E.; SHER, G.M.; JONES JUNIOR, J.N. Growing corn without tillage. Soil Science Society of America Proceedings, v.6, p.516-517, 1961.

POSSAMAI, J.M.; SOUZA, C.M.; GALVÃO, J.C.C. Sistemas de preparo do solo para o cultivo do milho safrinha. Bragantia, v.60, p.79-82, 2001.

RAIJ, B. van; CANTARELLA, H.; QUAGGIO, J.A.; FURLANI, A.M.C. Recomendações de adubação e calagem para o Estado de São Paulo. 2.ed. Campinas: Instituto Agronômico, 1996. 285p. (Boletim Técnico, 100).

RAIJ, B. van; QUAGGIO, J.A. Métodos de análise de solo para fins de fertilidade. Campinas: Instituto Agronômico, 1983. 31p. (Boletim Técnico, 81).

SANCHEZ, P.A.; LOGAN, T.J. Myths and science about the chemistry and fertility of soils in the tropics. In: LAL, R.; SANCHEZ, P.A. (Ed.). Myths and science of soil of the tropics. Madison: Soil Science Society of America, 1992. p.35-46. (Special Publication, 29).

SANTOS, H.P. dos; TOMM, G.O.; LHAMBY, J.C.B. Plantio direto versus convencional: efeito na fertilidade do solo e no rendimento de grãos da culturas em rotação com cevada. Revista Brasileira de Ciência do Solo. v.19, p.449-454, 1995.

SOUZA, C.M. Efeito do uso contínuo de grade pesada sobre algumas características físicas e químicas de um Latossolo Vermelho-Amarelo distrófico, fase cerrado, e sobre o desenvolvimento das plantas e absorção de nutrientes pela cultura de soja. 1988. 105p. Dissertação (Mestrado) - Universidade Federal de Viçosa, Viçosa.

WUTKE, E.B. Adubação verde: manejo da fitomassa e espécies utilizadas no Estado de São Paulo. In: WUTKE, E.B.; BULISANE, E.A.; MASCARENHAS, H.A.A. (Coord.). Curso sobre adubação verde no Instituto Agronômico. Campinas: Instituto Agronômico, 1993. p.17-29. (Documentos, 35).

Recebido em 5 de junho de 2003 e aprovado em 10 de outubro de 2003 